\title{
Bronchoscopic Lung Volume Reduction for Emphysema
}

\author{
Surya kant1* and Jyoti Bajpai \\ Department of Respiratory Medicine, University of Lucknow, India
}

Submission: March 10, 2017; Published: May 02, 2017

*Corresponding author: Surya kant, Department of Respiratory Medicine, University of Lucknow , India Tel: 9415016858 , Email: skantpulmed@gmail.com

\section{Background}

Emphysema is pathologically defined as an abnormal permanent enlargement of air spaces distal to the terminal bronchioles, accompanied by the destruction of alveolar walls and without obvious fibrosis [1]. It is an irreversible disease and although patients derive significant benefit from inhaled therapies and pulmonary rehabilitation but many remain significantly disabled [2]. Lung volume reduction surgery (LVRS) "reduction pneumoplasty" was first described in 1957 by Otto Brantigan [3] and was later reintroduced and refined by Joel Cooper [4]. The goals of lung volume reduction are to remove emphysematous lung to improve hyperinflation, diaphragmatic mobility and expiratory flow. The seminal trial was National Emphysema Treatment Trial (NETT) and results were published in 2003 which showed that a subset of patients who had upper lobe predominant emphysema and low baseline exercise capacity did benefit from LVRS and others did not [4].

Endoscopic lung volume reduction (ELVR) is a emerging management for advanced COPD. Valve implants, coil implants, biological LVR (BioLVR), bronchial thermal vapour ablation, and airway stents are used to induce lung deflation with the ultimate goal of improving respiratory mechanics and chronic dyspnea. Bronchoscopic lung volume reduction (BLVR) refers to any of the several bronchoscopic techniques for treating severe emphysema. This treatment was previously investigated in the randomized, controlled Endobronchial Valve for Emphysema Palliation Trial (VENT) [5], which showed significant but moderate improvements in forced expiratory volume in 1 second $\mathrm{FEV}_{1}$. Post hoc analyses of the VENT data suggested that endobronchial-valve treatment was more effective in patients who had a complete fissure (as compared with an incomplete fissure) between the lobe that was targeted for treatment and the adjacent lobe on high-resolution computed tomography (HRCT) and when endobronchial-valve treatment resulted in complete occlusion of the target lobe [5].
Endobronchial Lung Volume Reduction (ELVR) strategies include devices that completely occludean airway causing lobar collapse, that mechanically decrease the lung volume and mechanisms that induce inflammation and cause subsequent fibrosis thereby decreasing lung volume. Initially, complete bilateral upper lobe treatment was attempted, but this led to pneumothorax. Additionally, some patients were noted to have benefit without lobar collapse. This effect was postulated to be secondary to improvements in dynamic hyperinflation, collateral ventilation, ventilation/perfusion matching and redirection of ventilation to more functional alveolar units. The variables used to predict which form of bronchoscopic treatment would be most beneficial include collateral ventilation and disease heterogeneity [6]. Approaches have included the placement of endobronchial valves and, endobronchial coils, as well as biological agents to induce scarring and airway bypass approaches, either endobronchially or transpleurally .

\section{Bronchial Valves}

The working principle of endo/intra bronchial valves (EBVs or IBVs) is to allowair and secretions to come out while restricting air-entry, thus excluding the nonfunctional emphysematous region from ventilation and reducing dynamic air-trapping [7]. This procedure is suitable in heterogeneous, upper-lobe predominant emphysema without collateral ventilation. A limitation to this approach is the presence of inter lobar collateral ventilation. Where this occurs, occlusion of all segmental bronchi will not isolate a lobe, because air can still enter through pathological channels from adjacent damaged lung. There are two types of valve.

\section{Spiration intrabronchial valve}

Umbrella-shaped device with a nitinol frame consisting 5 distal anchors and 5 proximal struts with a central rod covered in a thin layer of polyurethane (Figure 1). 


\section{International Journal of Cell Science \& Molecular Biology}

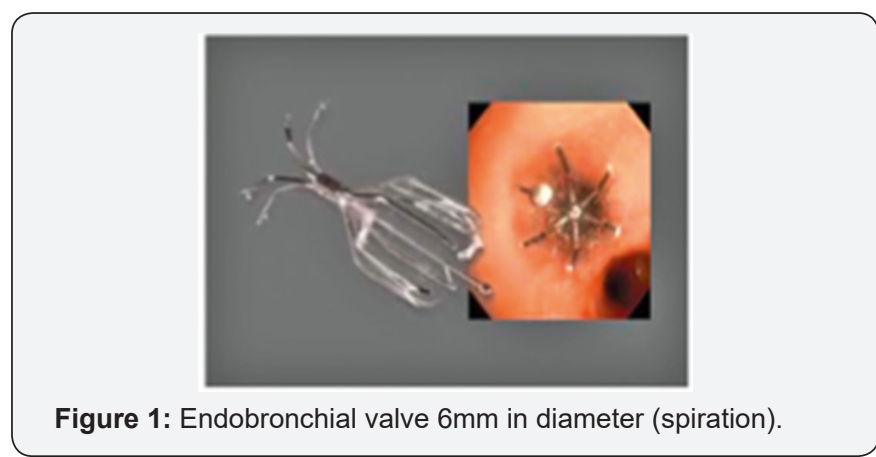

\section{Zephyr valve}

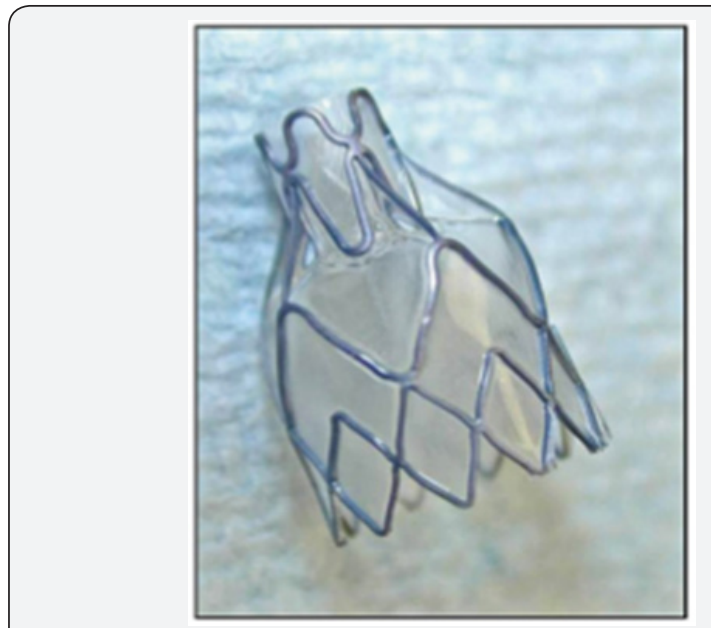

Figure 2: Endobronchial valve (zephyr) valve.

Duck-bill shaped, silicone-covered one way valve within a self-expanding stent that contains a flexible retainer which expands to anchor it to the airway and ensure an airtight seal (Figure 2). It is possible that up to 6 or more valves may be required for the complete blockade of a lobe. The procedure is usually performed under general anesthesia with patient intubated, on spontaneous assisted ventilation. EBVs by occluding airways increased the airway resistance thus diverting air to less emphysematous part of lung and decreasing airtrapping and dynamic hyperinflation is causes the inter lobar shift of ventilation from treated to untreated portion of lung thereby decreasing dead space and increasing ventilation thus reducing previously hypoxia induced vasoconstriction in the healthy areas of lung [8]. Is not only improves ventilationperfusion mismatch but also has beneficial effect on pulmonary hypertension [8] (Table 1). Surgical lung volume reduction is currently more effective than bronchoscopic lung volume reduction both in regard to changes in lung volumes and exercise capacity. However, morbidity and mortality are much lower in bronchoscopic lung volume reduction than with the surgical procedure. We have recently shown that implantation of a new generation of intra bronchial valves an umbrella-shaped, self- expanding device can be performed safely via flexible bronchoscopy under conscious sedation with propofol, even in patients with major contraindications for surgical volume reduction.
Table 1:

\begin{tabular}{|c|}
\hline Contraindications for Surgical Lung Volume Reduction \\
\hline Persistent smoking \\
\hline Not fit for pulmonary rehabilitation \\
\hline Pulmonary arterial hypertension (mPAP $>35 \mathrm{~mm} \mathrm{Hg}$ ) \\
\hline Very severe obstruction (FEV1 <20\% predicted) \\
\hline Severe impairment of gas exchange \\
\hline Diffusion capacity <20\% predicted \\
\hline Severe hypoxaemia \\
\hline Hypercapnia \\
\hline Major comorbidities \\
\hline Lung infection / bronchiectasis \\
\hline
\end{tabular}

\section{Biologic Lung Volume Reduction}

Fibrinogen suspension and thrombin solution, which polymerize to a hydrogel as they come in contact with one another induces a localized inflammatory reaction that causes atelectasis by occlusion and remodeling over 4- to 6-weeks.

A. Improves FEV1, FVC, RV/TLC, RV, dyspnea scores and SGRQ

B. Can be used in homogeneous disease, is not affected by collateral ventilation

C. Irreversible

\section{Aeriseal}

A. A synthetic version of biologic lung volume reduction system

B. No human blood products are used which decreases risk of transmissible diseases

C. Initially uses a primer to remove surfactant which causes atelectasis and then the synthetic hydrogel is introduced which causes inflammation resulting in scarring and remodeling over several weeks

D. Improves FEV1, RV and SGRQ

E. Has been studied in upper lobe predominant disease

F. Is not affected by collateral ventilation

G. Irreversible

\section{Bronchoscopic Thermal Vapor Ablation}

A. Use of heated water to produce thermal injury creating a localized inflammatory response followed by permanent fibrosis and atelectasis.

B. Studied in heterogeneous, upper-lobe predominant disease

C. Improves FEV1, RV, 6-minute walk distance, BODE index, SGRQ 
D. Not affected by collateral ventilation

E. Irreversible

\section{Coils}

A. Catheter loaded straightened nitinol coil over a guide wire. On coil deployment the straightened coil then conforms to its predetermined shape

B. Coil deployment bends the airway resulting in compression of adjacent lung tissue

C. Creates local lung volume reduction and restores elastic recoil of the healthier lung compartments.

D. Improves SGRQ, FEV1, RV and 6 minute walk distance

E. Not affected by collateral ventilation

F. Unclear if it can be reversed

\section{Airway bypass}

A. Initially created to treat homogeneous disease

B. Placement of drug-eluting stent-supported fenestrations in the airway wall to allow for decrease in air trapping and an increased volume of air expelled during forced exhalations

C. Was not successful: improvements were transient, the procedure is technically difficult and the stents are easily displaced or obstructed

A recently published randomized, controlled study, STELVIO, found that in patients with severe emphysema who were preselected on the basis of a proven absence of interlobar collateral ventilation, endobronchial-valve treatment improved pulmonary function, exercise capacity, and quality of life, even when we considered patients in whom valve removal was required. Adverse events, including potentially life-threatening events, occurred and required careful follow-up.

\section{Conclusion}

ELVR appears to be safe and will hopefully become an attractive minimally-invasive alternative for patients with severe COPD. Although, ELVR remains experimental, emerging data is promising. Refining patient selection and measurements to best qualify and quantify improvement outcomes is the current challenge.

\section{References}

1. Halbert RJ, Natoli JL, Gano A, Badamgarav E, Buist AS, (2006) Global burden of COPD: systematic review and meta-analysis. EurRespir J 28: 523-532

2. Brantigan OC (1957) Surgical treatment of pulmonary emphysema. Md State Med J 6: 409-414.

3. Cooper JD, Patterson GA, Sundaresan RS, Trulock EP, Yusen RD (1996) Results of 150 consecutive bilateral lung volume reduction procedures in patients with severe emphysema. J Thorac Cardiovasc Surg 112(5): 1319-1329.

4. Fishman A, Martinez F, Naunheim K, Piantadosi S, Wise R, et al. (2003) National Emphysema Treatment Trial Research Group. A randomized trial comparing lung- volume reduction surgery with medical therapy for severe emphysema. N Engl J Med 348(21): 2059-2073

5. Sciurba FC, Ernst A, Herth FJ (2010) A randomized study of endobronchial valves for advanced emphysema. N Engl J Med 363(13): 1233-1244.

6. Gompelmann D, Eberhardt R, Herth FJF (2013) Endoscopic Lung Volume Reduction A European Perspective Ann Am ThoracSocVol 10(6): 657-666.

7. Shah PL, Herth FJF (2014) Current status of bronchoscopic lung volume reduction with endobronchial valves Thorax 69(3): 280-286

8. Van Rikxoort EM, Goldin JG, Galperin-Aizenberg M (2012) A method for the automatic quantification of the completeness of pulmonary fissures: evaluation in a database of subjects with severe emphysema. EurRadiol 22(2): 302-309.

\section{Your next submission with Juniper Publishers} will reach you the below assets

- Quality Editorial service

- Swift Peer Review

- Reprints availability

- E-prints Service

- Manuscript Podcast for convenient understanding

- Global attainment for your research

- Manuscript accessibility in different formats

( Pdf, E-pub, Full Text, Audio)

- Unceasing customer service

Track the below URL for one-step submission https://juniperpublishers.com/online-submission.php 